УДК 669.162.1

\title{
ИССЛЕДОВАНИЕ ГАЗОДИНАМИЧЕСКОГО СОПРОТИВЛЕНИЯ СЛОЯ ПОЛИДИСПЕРСНОЙ АГЛОМЕРАЦИОННОЙ ШИХТЫ, ПОДГОТОВЛЕННОЙ К СПЕКАНИЮ
}

Мных А. С., канд. техн. наук, Яковлева И. Г., докт. техн. наук, Пазюк М. Ю., докт. техн. наук, Овчинникова И.А., канд. техн. наук

Запорожская государственная инженерная академия, пр. Ленина, 226, г. Запорожье, 69006, Украина

В роботі проведено дослідження 3 встановлення газодинамічного спротиву шару агломераційної шихти різного фракційного складу. Встановлено вплив сегрегації та швидкості фільтрації повітря на газодинаміку шару, що спікається.
В работе проведены исследования по определению газодинамического сопротивления слоя агломерационной шихты различного фракционного состава. Установлено влияние сегрегации и скорости фильтрации воздуха на газодинамику спекаемого слоя.
The paper studied to determine the flow resistance a layer sinter mix of different fractional composition. Identified effect of segregation and the rate of air filtration on the gas dynamics of sintered layer.

Библ. 11, табл. 1, рис. 6.

Ключевые слова: газодинамическое сопротивление, агломерационная шихта, фракционный состав.

\section{Введение}

Из теории агломерационного процесса известно, что для обеспечения успешного спекания шихты необходимо организовать интенсивное поступление воздуха в зону горения. Минимальная скорость фильтрации воздуха через слой, при которой возможно протекание реакции горения твердого топлива и образование жидкой фазы, должна составлять не менее $0,15 \ldots 0,2 \mathrm{~m}^{3} / \mathrm{M}^{2} \cdot \mathrm{c}$.

Агломерационная шихта относится к сыпучим материалам, состоящим из отдельных частиц, контактирующих друг с другом, между которыми находятся межкусковые каналы или поры. Принято считать, что газ в слое сыпучего материала или обтекает отдельные частицы, либо движется по извилистым, переменного сечения, каналам.

Учитывая сложность и многообразие характеристик стационарного слоя полидисперсного материала, для исследования процессов, протекающих в нем, целесообразно последний рассматривать как однородную массу, на каком-то конечном участке и использовать обобщенные характеристики, такие как порозность, удельная поверхность, коэффициент газодинамического сопротивления.

\section{Анализ исследований и публикаций}

Газопроницаемость представляет собой способность элементарного слоя с единичной поверхностью всасывания и высотой пропускать через себя то или иное количество газа в единицу времени, при определенном начальном разряжении под слоем [1].

Исследованиям газодинамики агломерационного слоя посвящена фундаментальная работа Коротича В.И., Пузанова В.П. [2]. Авторами получено двухчленное уравнение напора, в основу которого положено уравнение Дарси-Вейсбаха и коэффициент газодинамического сопротивления. Изложенная методика использована для количественного анализа газодинамического сопротивления различных зон слоя шихты с различным фракционным составом.

По данным Коршикова В.Г. [3], потеря напора газа в слое пропорциональна содержанию в шихте мелких классов - 0,5 мм. Увеличение массовой доли этой фракции от 8 до $24 \%$ сопровождается увеличением перепада давления $\triangle P$ с 10 до 40 кПа. На это же значение растет потеря напора при уменьшении среднегармонического диаметра гранул частиц шихты с 4,5 до 3,25 мм. 
В работе [4] Фролов Ю.А. предложил упрощенное уравнение для расчета потерь напора газа в слое шихты. Однако, для его использования необходимо проведение трудоемких экспериментов с целью определения эмпирических коэффициентов, учитывающих сопротивление всего слоя, и установления средних за процесс параметров газового потока.

Зависимость для определения потерь напора от высоты слоя, предложенная Петрушовым С.Н. [5], позволяет учесть влияние усадки слоя, частичного разрушения гранул, неравномерности слоя, содержания концентрата в шихте на газодинамику процесса. Автором установлено процентное соотношение влияния каждой составляющей на газодинамическое сопротивление слоя.

Значительное количество работ посвящено установлению влияния сегрегации на газодинамику агломерируемого слоя. Результаты подавляющего большинства исследований показывают, что сегрегация классов крупности шихты положительно влияет на структуру и газопроницаемость слоя [6,7]. Лишь некоторые исследователи отмечают вредное влияние сегрегации на распределение тепла и топлива в слое, а также на его газодинамику [8]. В своих опытах авторы наблюдали переоплавление поверхности слоя в связи с резким увеличением там содержания твердого топлива. В свою очередь, большое количество расплава, тем более в условиях применения внешнего нагрева, существенно снижало газопроницаемость слоя.

В работах $[9,10]$ отмечено, что при создании направленной сегрегации грансостава шихты по высоте слоя обеспечивается повышение прочности агломерата и увеличение производительности агломашин при одновременном сокращении расхода твердого топлива.

\section{Постановка задачи}

Анализ публикаций позволил сделать вывод, что газодинамическое сопротивление слоя оказывает значительное влияние на производительность агломерационного процесса и зависит от гранулометрического состава сырой шихты укладываемой на паллеты, ее сегрегации по высоте слоя, от типа применяемого загрузочного устройства. В связи с тем, что отечественные металлургические предприятия переходят на спе- кание шихты в высоких слоях 500 мм и более, исследование газодинамических характеристик слоя полидисперсной шихты является актуальной научной задачей для контроля и управления работой агломерационных машин.

Таким образом, в работе поставлены следующие задачи:

- установить зависимость коэффициента газодинамического сопротивления от числа Рейнольдса для полидисперсных смесей;

- исследовать влияние скорости фильтрации газа на потери давления в слое;

- проанализировать изменение общего сопротивления слоя от сегрегации шихты.

\section{Изложение результатов исследования}

К основным факторам, влияющим на газопроницаемость слоя сыпучих материалов, относится температура, влияющая на основные параметры газового потока - объем, плотность, вязкость. Исходя из того, что для определения потерь давления в массе сыпучих полидисперсных материалов слой шихты разбивали на участки, данные слои принимались как однородные изотермические.

Наиболее важной газодинамической характеристикой пористого слоя является его сопротивление, которое слагается из сопротивления трения и местных сопротивлений. Доля местных сопротивлений по отношению к общему значительно выше, а при $\mathrm{Re}>2000$, превосходит $95 \%$, поэтому потери в пористом слое $\Delta P$ определялись на основании расчета местных сопротивлений при движении газа по каналам. Для описания потерь давления в слое использована интерпретация общего для всех сыпучих материалов уравнения Дарси-Вейсбаха, описывающего канальное течение газа при наличии трения в канал

$$
\Delta P=K_{c л} \frac{\omega^{2}}{2} \rho(1+\beta T),
$$

где: $\omega$ - скорость газового потока, м/с; $\rho$ - плотность газового потока, кг/ $\mathrm{M}^{3} ; \beta-$ коэффициент объемного расширения газа $\left(0,003661 K^{-1}\right) ; T-$ температура газа, $K ; K_{\text {сл }}$ - коэффициент, комплексно учитывающий влияние неопределенности форм и размеров пор

$$
K_{c l s}=4 \psi_{c r} \frac{H}{d_{\ni}}
$$


где: $\Psi_{c л}$ - коэффициент газодинамического сопротивления, (Па·м $\left.c^{2}\right) / к г ; H-$ высота слоя, м; $d_{\text {э- }}$ эквивалентный диаметр пор, м.

При расчетах потерь давления в реальных условиях использованы экспериментальные значения $\Psi_{c л}$. Последние получены в условиях лаборатории комбината «Запорожсталь». Опытная установка представляет собой спекательную чашу в виде усеченной пирамиды размером $0,5 \times 0,5 \times 1,2 \mathrm{M}$, толщина стенок $8 \mathrm{MM}$, заполненной полидисперсной шихтой, лежащей на колосниковой решетке и эксгаустера, создающего разреже- ние под слоем.

Предварительно шихта рассеивалась на фракции размером: $3,3 \ldots 5,5 \ldots 8$ и 8 мм. Изначально опыты проводились как с чистыми фракциями, так и с комбинированными попарно. На следующем этапе комбинировались все 4 фракции, их состав в смеси задавался, исходя из того, что определяющей при вычислении сопротивления является фракция 3 мм. Ее количество относительно массы всей смеси изменялось с 10 до $60 \%$. Изменение остальных составляющих смеси представлено в табл. 1.

Таблица 1. Содержание фракций полидисперсной шихты

\begin{tabular}{|c|c|c|c|c|c|}
\hline & \multicolumn{4}{|c|}{ Фракции, \% } & \multirow[b]{2}{*}{$d_{c p}, \mathrm{MM}$} \\
\hline № & $\Phi 1(3, \mathrm{MM})$ & $\Phi 2(3 \ldots 5, \mathrm{MM})$ & $\Phi 3(5 \ldots 8, \mathrm{Mм})$ & $\Phi 4(8, \mathrm{MM})$ & \\
\hline 1 & 10 & 30 & 30 & 30 & 6,3 \\
\hline 2 & 20 & 20 & 30 & 30 & 6,05 \\
\hline 3 & 25 & 25 & 25 & 25 & 5,5 \\
\hline 4 & 30 & 30 & 30 & 10 & 4,6 \\
\hline 5 & 40 & 25 & 25 & 10 & 4,225 \\
\hline 6 & 50 & 20 & 20 & 10 & 3,85 \\
\hline 7 & 60 & 20 & 10 & 10 & 3,35 \\
\hline
\end{tabular}

При проведении экспериментов фильтрующая среда (воздух $T=20^{\circ} \mathrm{C}$ ) проходила в спекательную чашу, просасываясь сквозь слой шихты сверху вниз и по газоходу через эксгаустер выбрасывалась в атмосферу. В процессе работы контролировалась скорость фильтрации среды при помощи анемометра и потери давления в слое для каждого режима эксгаустера. На основе полученных данных рассчитан критерий Рейнольдса и соответствующие ему коэффициенты сопротивления слоя $\psi_{\text {сл }}$

$\operatorname{Re}=\frac{\omega \cdot d_{\ni}}{v(T)}$

где $v$ - кинематическая вязкость воздуха, $\mathrm{M}^{2} / \mathrm{c}$,

$d_{\ni}=\mu \frac{\varepsilon}{1-\varepsilon} d_{c p}$

где: $\mu$ - коэффициент формы частиц шихты (для шара $\mu=2 / 3)$; $\varepsilon-$ порозность слоя, которая в зависимости от типа укладки может быть описана уравнением Слихтера:

$\varepsilon=1-\frac{\pi}{6(1-\cos \gamma) \sqrt{1+2 \cos \gamma}}$, где: $\gamma$ - угол между прямыми, проходящими через центы шарообразных частиц, град.

$d_{c p}=\frac{\sum_{i=1}^{n} d_{i} \Phi_{i}}{\sum_{i=1}^{n} \Phi_{i}}$

где: $D_{i}-$ средний диаметр $i$-й фракиции, м; $\Phi_{i-}^{-}$ содержание $i$-й фракиции в смеси, $\% ; n-$ количество фракций в смеси.

Коэффициент газодинамического сопротивления слоя $\psi_{c л}$, соответствующий числу Re, вычислялся согласно формулы:

$\psi_{c л}=\frac{\Delta P d_{\ni}}{2 H \omega^{2} \rho(1+\beta T)}$.

Результаты исследований сведены в графики критериальных зависимостей для смесей шихты различного фракционного состава, рис. 1, 2.

В работе [11] получено требуемое распределение фракционного состава шихтовых материалов, подготовленных к спеканию в слое высотой 
500 мм. Результаты расчетов газодинамического сопротивления по горизонтам данного слоя приведены на рис. 3, 4. Анализ полученных результатов показал, что наравне с сегрегацией гранул по высоте существенное влияние на газодинамику слоя оказывает скорость движения воздуха и фракционный состав исходной шихты.

Следует отметить, что значительный перепад давления в верхнем горизонте слоя, вызванный

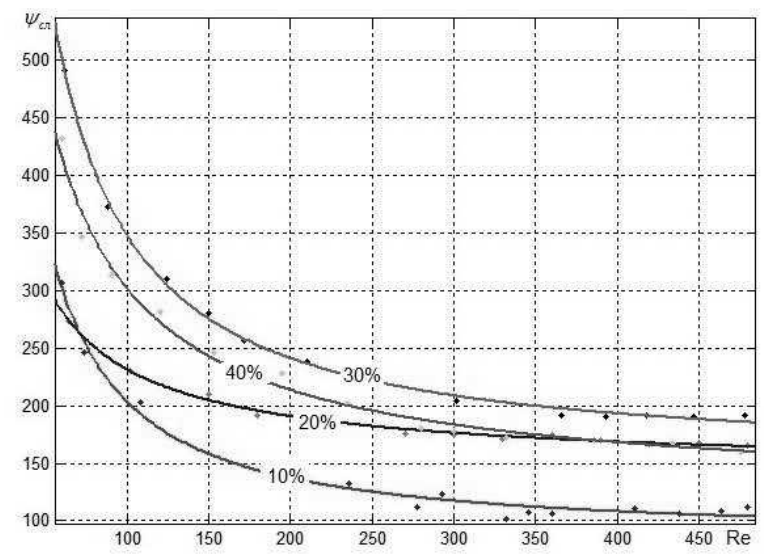

Рис. 1. Зависимость $\psi_{\text {. }}=f(\mathrm{Re})$ для смесей, содержащцих 10...40 \% фракции 3 мм.

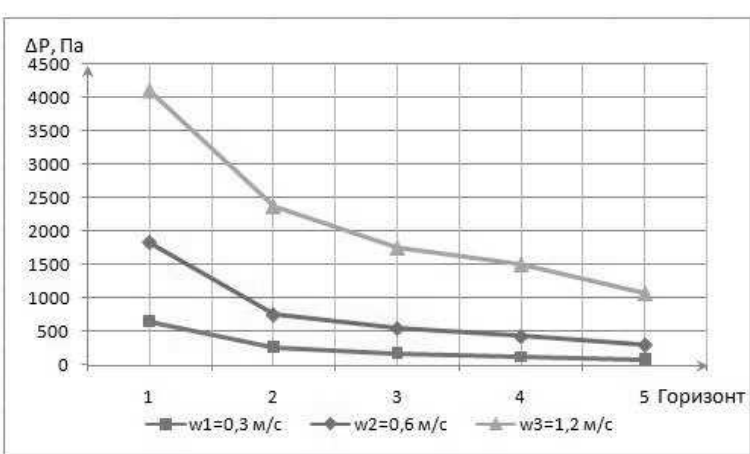

Рис. 3. Влияние скорости фильтрации газа на потери давления в горизонте.

Особый интерес представляет определение газодинамических характеристик колосников. Сопротивление колосников определяется их состоянием и формой. Под состоянием понимается степень засорения колосника частицами и кусочками шихты. Так, исследования, проведенные в [4], показали, что при реальных параметрах газа в свободной от материала решетке потери давления составляют $40 \ldots 70$ Па, а в рабочих условиях аглофабрик этот показатель составляет $0,11 \ldots 0,47$ кПа. При залипании колосника ме- повышенной концентрацией $(60 \ldots 80$ \%) мелкодисперсной (3 мм) окомкованной шихты характерен для сырого слоя без влияния внешнего источника теплоты. При зажигании горном твердого топлива в слое шихты, в ней, за счет испарения влаги, интенсифицируются процессы порообразования, что влечет за собой снижение газодинамического сопротивления верхнего горизонта до $0,55 \ldots 0,60$ кПа.

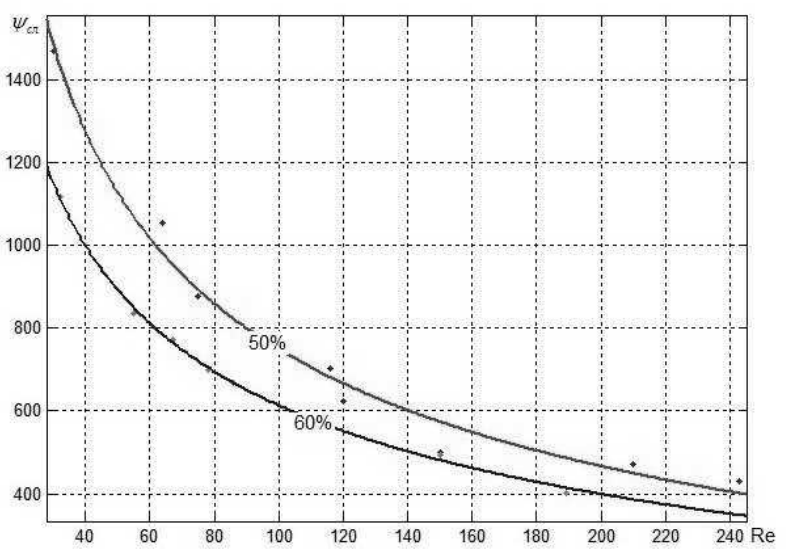

Рис. 2. Зависимость $\psi_{\text {с }}=f(\mathrm{Re})$ для смесей, содержсащих 50 и 60 \% фракции 3 мм.

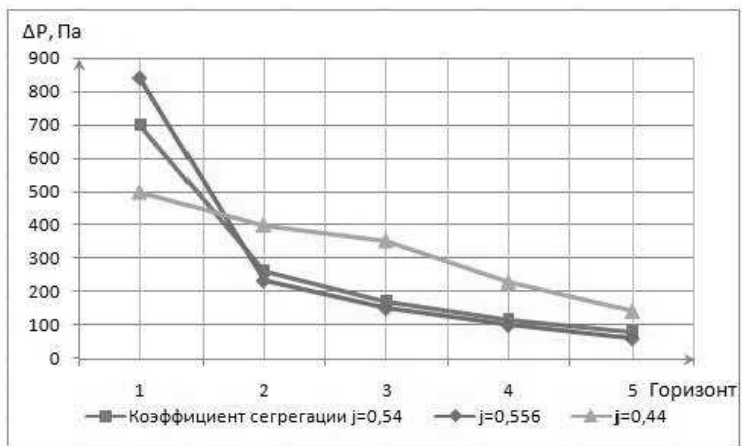

Рис. 4. Влияние сегрегации на потери давления в горизонте.

лочью потери давления возрастают и достигают значения $0,9 \ldots 1,0$ кПа.

Форма колосников влияет следующим обра3ом: сопротивление ромбических колосников на 20...30 \% меньше, чем прямоугольных, а наибольшим сопротивлением обладает полукруглая в верхней части решетка: потери давления в них достигают 3 кПа.

На агломерационных машинах комбината «Запорожсталь» паллеты оборудованы колосниками прямоугольной формы самоочищающейся 
конструкции. Это позволило обеспечить потери напора в колосниковом поле на уровне $0,20 \ldots$ 0,35 кПа.

В связи с вышеизложенным, необходимо иметь в виду, что величина потерь давления в спекательной тележке отражает газодинамическое состояние слоя с определенной долей погрешности. Значение коэффициента сопротивления слоя, определенного для этого значения потерь давления, будет завышено на 20...30 \%.

Для учета влияния на газодинамику спекаемого слоя таких факторов, как усадка слоя, частичное разрушение гранул и т.д., использована следующая зависимость [5]:

$\Delta P_{c y M}=\Delta P \cdot H+\Delta P_{1}(H-1)+\Delta P_{2}(H-2)^{2}+$

$+\Delta P_{3}(H-3)^{3}+G \cdot H$,

где: $\Delta P_{1}-$ сопротивление за счет усадки $(0,01 \ldots 0,05)$, кПа; $\Delta P_{2}-$ сопротивление, возникающее при частичном разрушении гранул $(0,01 \ldots 0,03)$, кПа; $\Delta P_{3}-$ сопротивление, учитывающее неравномерность изменения структуры слоя по высоте $(0,03)$, кПа; $G$ - коэффициент, характеризующий количество мелкой фракции (3 мм) в шихте (при $20 \%$ мелочи $G=0$, при $30 \%$ $-G=1$ и т.д.).

Таким образом, общее газодинамическое

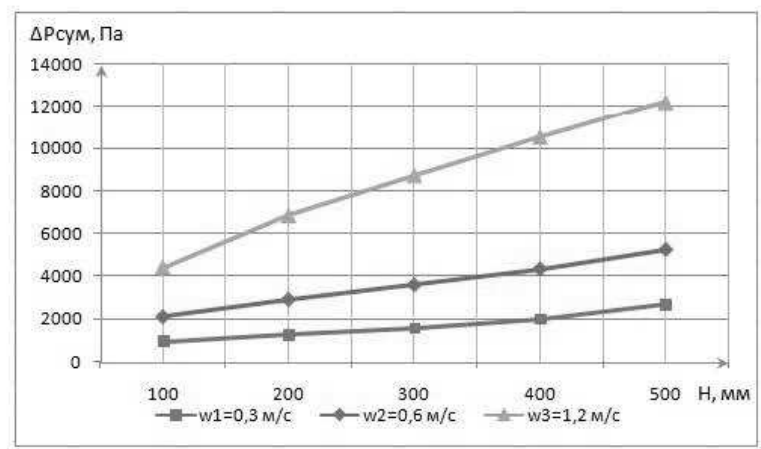

\section{Рис. 5. Изменение газодинамики слоя от ско- рости фильтрации воздуха.}

\section{Выводы}

Проведенные исследования по определению потерь давления в массе полидисперсных материалов, подготовленных к спеканию, позволили установить зависимости $\psi_{c л}=f(\mathrm{Re})$ от фракционного состава шихты.

Определены потери давления в слое высотой сопротивление спекаемого слоя высотой 500 мм изменяется в зависимости от скорости фильтрации воздуха и фракционного состава шихты и представлено на рис. 5, 6.

Исходя из результатов исследований можно сделать вывод, что увеличение скорости фильтрации воздуха через слой спекаемой шихты прямопропорционально увеличивает газодинамическое сопротивление слоя и, как следствие, перегружает тягодутьевое оборудование агломерационной машины и увеличивает расход электроэнергии.

Влияние сегрегации не однозначное. При низком значении коэффициента сегрегации прослеживается минимальное падение $\Delta P$ в верхнем горизонте $0 . .100$ мм. Однако следует учесть, что при таком распределении фракционного состава не обеспечивается требуемое содержание твердого топлива в верхних слоях шихты, и, как следствие, происходит нарушение теплового режима спекания. При высоком значении $j$ начальный $\Delta P$ в верхнем горизонте наибольший за счет концентрации там мелкой фракции, являющейся основным носителем твердого топлива, что позволяет добиться требуемой температуры спекания, а увеличение содержания крупных фракций шихты в нижних горизонтах снижает общие потери давления в слое.

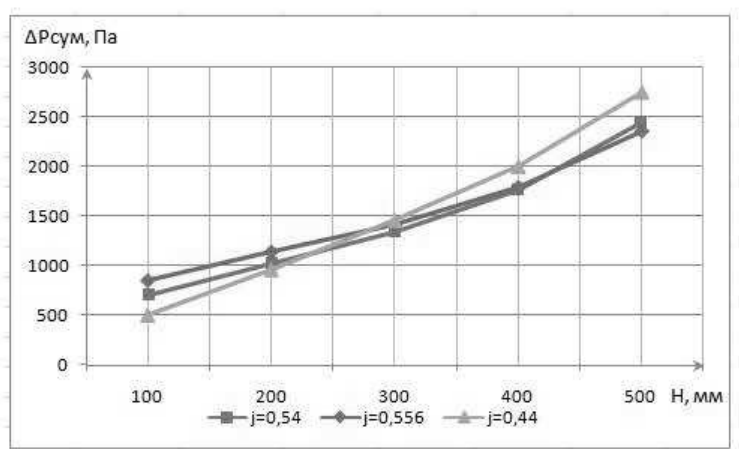

\section{Рис. 6. Изменение общего сопротивления слоя от сегрегации иихты.}

500 мм в зависимости от скорости фильтрации воздуха и сегрегации шихтовых материалов по высоте. Установлено, что увеличение скорости фильтрации воздуха от 0,3 до 1,2 м/с, увеличивает газодинамическое сопротивление слоя в 5 раз, а усиление сегрегационных процессов в слое позитивно влияет как на тепловой режим спекания, 
так и на газодинамику слоя.

Результаты исследований создают предпосылки к постановке оптимизационной задачи с разработкой алгоритма управления загрузочным устройством агломашины, с целью формирования слоя шихты с минимальным $\triangle P$ и требуемым распределением твердого топлива по высоте спекательной тележки.

\section{ЛИТЕРАТУРА}

1. Авдеенко A.A. Оперативное определение газодинамического сопротивления слоя агломерационной машины / А.А. Авдеенко, Ю.Г. Клейн // Известия ВУЗов. Черная металлургия. - 1998. - №12. - C.6-10.

2. Коротич В.И. Газодинамика агломерационного процесса / В.И. Коротич, В.П. Пузанов. М.: Металлургия, 1969. - 206 с.

3. Коршиков Г.В. Влияние строения структурных элементов агломерационной шихты на газодинамическую характеристику спекаемого слоя / Г.В. Коршиков, М.А. Хайков, Н.Н. Должикова // Известия ВУЗов. Черная металлургия. 1983. - №6. - С.12-15.

4. Фролов Ю.А. Анализ газодинамической работы агломерационных машин/ Ю.А. Фролов // Сталь. - 2005. -.№6 - С. 42-51.

5. Петрушов С. Н. Формирование слоя шихты на агломашине: Курс лекций / С. Н. Петрушов // Алчевск: ДонГТУ. - 2006. - 187 с.
6. Исследование и совершенствование укладки шихты на агломашину / С.Н. Петрушов, А.П. Полухин, Л.М. Рудаков, А.И. Капуста [и др.] // Теплотехника и газодинамика агломерационного процесса: сборник. - Киев: Наукова думка, 1983. - C.29-33.

7. Matsumura T. Development of new feeding equipment for controlling charge segregation of sinter feed / T. Matsumura, S. Amano, H. Asahara.// Current Advances in Materials and Processes. 1999. - №4. - P 766.

8. Фролов Ю.А. Исследование сегрегации агломерационных шихт / Ю.А. Фролов, С.Г. Братчиков, Е.Е. Заславский // Сталь. - 1974 - №10. C. 882-886.

9. Пазюк М.Ю. Исследование сегрегации топлива в слое шихты / М.Ю. Пазюк, В.И. Гранковский // Известия ВУЗов. Черная металлургия. - 1982. - №12. - C.6-8.

10. Nakano M. Sintercake Structure Offering High Productivity and High Yield / M. Nakano, T. Kawaquchi, S. Kasama. // ICSTI Ironmaking Conference Proceedings. - 1996. - P.183-190.

11. Mrblх A.C. Определение оптимального распределения твердого топлива в слое загружаемой шихты для выравнивания теплового режима агломерационного процесса / А. С. Мных // Технічна теплофізика та промислова теплоенергетика. - 2014. - №6. - С. 47-51. 


\section{THE STUDY OF GAS-DYNAMIC RESISTANCE OF THE LAYER OF AGGLOMERATION CHARGE, PREPARED FOR SINTERING}

\section{Mnyh A.S., Yakovleva I.G., Pazuk M.U., Ovchinikova I. A.}

Zaporozhye state engineering Academy, Lenina 226, Zaporozhye, Ukraine, 69006.

The paper studied to determine the flow resistance a layer sinter mix of different fractional composition. Identified effect of segregation and the rate of air filtration on the gas dynamics of sintered layer. References 11, table 1, figures 6.

Key words: gas-dynamic resistance, agglomeration charge, fractional composition.

1. Avdeenko, A.A. (1998). The operational definition of the gas-dynamic resistance of the layer of sinter machine, Chernaya Metalurgiya, №.12, P. 6-10.

2. Korotich, V.I. (1969). The dynamics of the agglomeration process, Metalurgiya, Moscow 206 p.

3. Korshikov, G. V. (1983). The influence of the structure of the structural elements of the agglomeration of the charge on the gas-dynamic characteristics of the sintered layer, Chernaya
Metalurgiya, №.6, P. 12-15.

4. Frolov, U.A. (2005). Analysis of gas-dynamic operation of sintering machines, Stal, No 6, P. 42-51.

5. Petrushov, S. N.(2006). Forming a layer of charge on the sintering machine, DonSTU, Alchevsk, $182 \mathrm{p}$.

6. Petrushov, S.N. (1983). The study and improvement of the laying of the charge on the sintering machine, Heat engineering and gas dynamics of the agglomeration process: collection. - Kiev: Naukova Dumka, P. 29-33.

7. Matsumura, T. Development of new feeding equipment for controlling charge segregation of sinter feed / T. Matsumura, S. Amano, H. Asahara.// Current Advances in Materials and Processes. 1999. - №4. - 766 p.

8. Frolov, U.A. (1974). Investigation of segregation of sinter mix, Stal, №.10, P. 82-86.

9. Pazuk, M.U. (1982). Investigation of segregation of fuel in the batch blanket, Chernaya Metalurgiya, №.12, P. 6-8

10. Nakano, M. Sintercake Structure Offering High Productivity and High Yield / M. Nakano, T. Kawaquchi, S. Kasama. // ICSTI Ironmaking Conference Proceedings. - 1996. - P. 183-190.

11. Mnyh, A.S. (2014), Determination of the optimal distribution of the solid fuel layer downloadable charge to align the thermal regime of the sintering process., Tehnicheskaya teplophizika I promishlenaya teploenergetika, №.6, P. 47-51. 